\title{
Factors Favouring Cholelithiasis in North Indian Population
}

\author{
Anamika Gaharwar \\ Department of Anatomy, GSVM Medical College, Kanpur.
}

\begin{abstract}
The present study was done on 132 cases those underwent cholecystectomy for benign Gall Bladder disease. Our study concluded that maximum, 58 cases(43.94\%) number of cases were in the age group of 41-50 years followed by 30 cases in 31-40 years of age group. 121 cases(91.66\%) were females and 11 cases $(8.33 \%)$ were males. 18 cases( $12 \%)$ were diabetic and 114 cases (88\%) were non-diabetic. Among 121 females $78(64.6 \%)$ were taking oral contraceptives and $43(35.4 \%)$ were not taking oral contraceptives. We observed that high incidence of Gall Stone is in the age group of 40-50 years, Females on Oral Contraceptive Pills are more prone for cholelithiasis. Diabetes promotes Bile stasis and Gall Bladder stones
\end{abstract}

KEYWORDS: Gallstones, cholelithiasis, Gall bladder, Risk Factors.

\section{INTRODUCTION}

The introduction of Gall Bladder disease to mankind dates back to the 21st Egyptian Dynasty (1085945 BC), when gall stones were discovered in the mummy of priestess of Amen. Williams et al (1989) described Gall bladder as slate blue, pyrifom sac sunken in fossa in the right hepatic lobe s inferior surface .It is $7-8 \mathrm{~cm}$ long . $3 \mathrm{~cm}$ broad at the widest and $30-50 \mathrm{ml}$ in capacity. Dimerbroek over 300 years back, appreciated that bile enters the gall bladder to acquire greater strength and digestive power and since then many studies have increased our knowledge of its function.A Fat,Fertile, Flatulent, Female of 50 years is classic sufferer of Gall Bladder stones. Gall Stones are classified according to their chemical composition in to Cholesterol stones, Mixed stones and Pigment stones. Mixed Stones account for $90 \%$ of gall stones. Cholesterol is the main component others are calcium bilirubinate, calcium phosphate, calcium carbonate, calcium palmitate and proteins. Usually they are small and multiple. (R C G Russel et al , 2000). The prevalence of Gall stones increases with advancing age and it is due to increase in cholesterol content in Bile. Study by Grepco and Sirmione found that Gall stones prevelance rates increases with advancing age. Zuhair R. et al reported peak age of incidence as $41-50$ years. His study also concluded that Female :Male ratio for gall stone disease is 4:1.Oestrogenic influences including Oral Contraceptive Pills (OCPs) intake and pregnancies increase the expression of hepatic lipoprotein receptors.

Diabetes increases risk of cholelithiasis. Bennion and Grundy in 1977 reported increase bile salt synthesis, expanded bile acid pool and decreased cholesterol saturation in obese diabetics.Correlation of incidences of cholelithiasis with age, sex; diabetes and OCP intake were studied in detail.

\section{MATERIALS AND METHODS}

The study was done in department of Anatomy in association with department of Surgery and department of Pathology, GSVM Medical College Kanpur. . Total 132 cases were selected for study. After cholecystectomy the specimens were collected and fixed in $10 \%$ formalin and well labelled. Along with specimen complete detailed history of the cases were taken for study. The gross and histopathological examinations were also made to confirm the cholelithiasis.

\section{OBSERVATION}

The prevalence of risk factors, sex, diabetes and OCP intake in females were analysed in 132 cases .The age of cases was considered from new born to 70 year. The observations were grouped after every 10 year. In 0-10 age group and 11-20 age groups only one $(0.76 \%)$ case of cholelithiasis was found. We noticed 18 cases $(13.64 \%)$ in $21-30$ age group, 30(22.72 \%)cases in 31-40 age group, 58(43.94 \%)cases in 41-50 age group. $20(15.15 \%)$ cases in 51-60 age group and 4 cases $(3.03 \%)$ in 61-70 age group .(Table-I) .In this study 121 ( $91.66 \%$ ) patients were female and $11(8.33 \%$ ) were males.(Table-II). Among 121 female patients 78 were taking OCPs containing oestrogens and 43 were not taking OCPs. .(Table-IV) Out of 132, 18 cases were known Diabetic.(Table-III) 
Table - I - Age wise distribution of Gall Bladder disease

\begin{tabular}{|c|c|c|}
\hline $\begin{array}{c}\text { Age group } \\
\text { (in years ) }\end{array}$ & Number of cases & Percentage \\
\hline $0-10$ & 1 & $0.76 \%$ \\
\hline $11-20$ & 1 & $0.76 \%$ \\
\hline $21-30$ & 18 & $13.64 \%$ \\
\hline $31-40$ & 30 & $22.72 \%$ \\
\hline $41-50$ & 58 & $43.94 \%$ \\
\hline $51-60$ & 20 & $15.15 \%$ \\
\hline $61-70$ & 4 & $3.03 \%$ \\
\hline
\end{tabular}

$\underline{\text { Table-II Sex wise distribution of Gall Bladder disease }}$

\begin{tabular}{|c|c|c|}
\hline Sex & Number of cases & Percentage \\
\hline Female & 121 & $91.66 \%$ \\
\hline Male & 11 & $8.33 \%$ \\
\hline
\end{tabular}

Table - III : Prevelance of Gall stones among Diabetes Mellitus

\begin{tabular}{|c|c|c|}
\hline Feature & Number & Percentage \\
\hline Diabetic & 18 & $12 \%$ \\
\hline Non-Diabetic & 114 & $88 \%$ \\
\hline
\end{tabular}

Table - IV: prevalence of Gall Stones among females on OCPS

\begin{tabular}{|c|c|c|}
\hline Feature & Number & Percentage \\
\hline Taking OCP & 78 & $64.6 \%$ \\
\hline Not Taking OCP & 43 & $35.4 \%$ \\
\hline
\end{tabular}

\section{DISCUSSION}

Study conducted by Barbara et al in 1987 reported prevelance of Gall stones peaking in 50-60 years. Further study of Ranshoff and Gracie in 1993 concluded same result. In our present study maximum cases were in the age group of 41-50 years which is little bit earlier than above mentioned. This discrepancy is due to most of the female patients in our study were from countryside having early marriage, early child bearing and frequent pregnancies. This resulted in increased exposure of Gall Bladder to progesterone for which receptors are present on Gall Bladder wall which was documented by Henriksson et al in 1989.Calabrese C , et al reported less than $5 \%$ of cholecystectomies performed are in the patients less than $20 \mathrm{yrs}$ of age. In Sirmione study concluded only 1 case in age group of 18-21 years out of 135 cases have gall stones demonstrated by Ultrasound. Study of Tandon R. K. Concluded that average age of patiets in India is a decade younger than those in the west. Studies by Jayanthi V.et al have shown increase in the prevalence of Gall stones with age probably because of dec rease in activity of cholesterol a reductase, and increase in activity of HMG CO A reductase resulting in increase cholesterol secretion and saturation of bile.

In all literature available so far females have been the easiest victim of Gall Stone Disease .It was documented in study of Henriksson Peter in 1989 that human Gall Bladder wall have estrogen and progesterone receptors. In our study $121(91.66 \%)$ patients were female and $11(8.33 \%)$ were males. T M. H. Alwam reviewed 894 cholecystectomy specimens in 1984 reported female predominance with female; male ratio 3:1 and mean age as 45 years. Such gender ratio and age distribution has great similarities to results concluded by study of Mahgoub E. S. And Malaika S.

H. Mohan studies reported preponderance of female with male :female ratio 1:6.4. Tandon RK , Dhar SC, Baig SJ also reported predominance of female among patients withGall stone disease. Infact female sex hormones and Sedentary habits of most women in India exposes them to factors that probably promote the formation of Gall stones

Among 121 female patients 78 were taking OCPs containing oestrogens and 43 were not taking OCPs .This result is supported by Bennion et al in 1976 who concluded that bile becomes more lithogenic when women are placed on OCPs containing oestrogen .Further relatively more casual relationship between oestrogen and Gall Stones was suggested by study showing increase lithogenicity of bile and biliary stone formation in males given estrogen for Carcinoma Prostate.This was concluded by Henriksson et al (1989). Johnston $\boldsymbol{a l}$; 1988 stated that increase in number of pregnancies is associated with increased risk of Gall Stone disease.Howat J.M. et al concluded that there is correlation between use of oral contraceptives and increased risk of Gall stones formation. Large doses of estrogen have been shown to change Bile flow and composition. These changes are responsible for increased incidence of Gall stones in premenopausal women on 
oral contraceptives. Grodstein F et al concluded no substantial increase in risk of symptomatic Gall stones among ever ocp users, although current and long term users had somewhat increased risk.

18 out of 132 were known Diabetic in our present study.This reflets association of Diabetes with Gall Stones.A particular disposing factor in diabetes is an impairment of Gall Bladder emptying which may be related to presence of Autonomic neuropathy.Studies of Ikrad R.W. concluded increased incidence of Gall stones in Diabetic patient. The principal Gall bladder pathologic feature in diabetic patient is functional deficit of uncertain etiologic factors creating a large flaccid, poorly emptying organ.

Among 132 cases 79 were vegetarian and 53 were Non-vegetarian but correlation between diet and Gall Bladder Stones cannot be concluded as majority of Indian population are vegetarian.

\section{CONCLUSION}

Following conclusions have been derived from our present study:-

- Peak incidence of Gall Stone is in the age group of 40-50 years.

- Females on Oral Contraceptive Pills are more prone for cholelithiasis as oestrogens present in OCPs causes bile to become more lithogenic.

- Diabetes promotes Bile stasis and Gall Bladder stones.

- Cholelithiasis is more prevalent in females

\section{REFRENCES:}

[1]. Russel RCG,Williams NS, Blustrade GJK - Bailey stones. Short Practice of surgery , 23 Edition Arnold Publishers , 20009,74 973

[2]. Dimerbroek, Anatome Corporis humani Utrecht :1672.

[3]. GREPCO ,The Epidemiology of gall stone disease in Rome , Italy .part 1 Hepatology ; 8: 1988 904-913

[4]. Zuhair R, Al Bahrani Hani mohammad, Saleh AL Ansari Prevelance and Morphology and chemical composition of Gall stones The Iraqi Post graduate medical Journal vol. 10 No.1, 2011

[5]. Bennion LJ,Genoberg RL, Effect of oral contracepyives on the Gall stone disease Bile of normal women N. England J.Med 294 : 189,1976

[6]. Barbara L,Sama C, Morselli Labate AM, Taroni F, RusticaAG, Festi D, Sapico C, Roda E, Banterle C, Pauci A, et al Clinica Medica, Universita, Bologna Italy Hepatology sep-oct , 7(5) 1989:913-17

[7]. Gracie WA,Ranshoff DF The natural History of silent gall stones N. England J. Med. ; 307 1982: 798-800

[8]. Henriksson P, Eianarsson K, Estrogen induced gall stone formation in males J.Clinical Invest. 84, $1989: 811$

[9]. Calabresse C,Pearlman DM Gall Ballader Disease in age group of 21 years 70: 1971; 413-417

[10]. Tandon R K Pathogenesis of Gall stone in India. ; 9 Trop Gastroenterol 1988:83-91.

[11]. Jyanthi V, Pattern of Gall stone disease in Madras city south India , a hospital based survey. J. Associated phys India ;44: 1996 461-64

[12]. M H Alwan. Incidence of cholelithiasis in Kuwait : A review of 894 cases Arab J. Med., $1984 ; 3: 17-20$

[13]. Mahgoub ES And Malaika S The microbiology of cholecystitis in Riyadh Saudi Med J 9, 1988:169-172

[14]. H Mohan, RPS Punia, SB Dhawan,S Ahal, MS Sekhar Department of pathology and surgery Government medical college and hospital Chandigarh India Morphological spectrum of Gall stone disease in 1100 cholecystectomy specimens in north India . Indian journal surgery;67: 2005 140-42

[15]. Dhar SC, Ansari S, Saha M, Ahmad MM, Rahman MT, Hasam M et al. Gall stone disease in rural Bangladesh community Indian journal Gastroentrology; 20, 2001:223-6

[16]. Baig SJ, Biswas S, Das S ,Basu k, Chattopadhya G Histopathological changes in Gall bladder mucosa in cholelithiasis Trop Gastroentrology Jan-Mar 23 (1) 2002:25-27

[17]. Johnston DE, Kalpana M M Pathogenesis and treatment of Gall stones N. England MED 328 : 412,1993

[18]. Howat JM , Jones CB , Schofield PF . Gall stone and oral contraceptives J. Internal media Research 3(2) 1975 ;:nn59-62

[19]. Grodstien T, Colditz G A, Hunter DJ , Manson JE, Willet WC ,Stampfer MJ Department of epidemiology, Harvard school of public health , Boston , Massachusetts obst. and gynae , 84 (2) 1994: 207-214

[20]. Ikrad RW Department of surgery, Vanderbit university, Nashville, Tennesse. Surgery, Gynae and obs171 (6) 1990 ,; $528-$ 532 